\title{
Meta-Analysis
}

\section{e Comparative Efficacy and Safety of Six Antidepressants and Anticonvulsants in Painful Diabetic Neuropathy: A Network Meta-analysis}

Neelima Rudroju, MPharm', Dipika Bansal, MD, DM', Shiva Teja Talakokkula, MPharm', Kapil Gudala, PhD', Debasish Hota, MD, DM², Anil Bhansali, MD, DM³, and Babita Ghai, MD ${ }^{4}$

From: ${ }^{1}$ Clinical Research Unit, Department of Pharmacy Practice, National Institute of Pharmaceutical Education and Research, SAS Nagar (Mohali), India-160062; '2Department of Pharmacology, Postgraduate Institute of Medical Education and Research, Chandigarh, India; ${ }^{3}$ Department of Endocrinology, Postgraduate Institute of Medical Education and Research, Chandigarh, India; ${ }^{4}$ Department

of Anaesthesia, Postgraduate

Institute of Medical Education and Research, Chandigarh, India

Address Correspondence: Dr. Dipika Bansal Assistant Professor Clinical Research Unit, Department of Pharmacy Practice,

National Institute of Pharmaceutical Education and Research, S.A.S. Nagar (Mohali)-160062, Punjab, India E-mail:

dipikabansalo79@gmail.com

Disclaimer: There was no external funding in the preparation of this manuscript. Conflict of interest: Each author certifies that he or she, or a member of his or her immediate

family, has no commercial association (i.e., consultancies, stock ownership, equity interest, patent/licensing arrangements, etc.) that might post a conflict of interest in connection with the submitted manuscript.

Manuscript received: 05-17-2013 Revised manuscript received: 06-26-2013

Accepted for publication: 07-01-2013

Free full manuscript: www.painphysicianjournal.com
Background: Anticonvulsants and antidepressants are mostly used in management of painful diabetic neuropathy (PDN). However there are few direct comparisons between drugs of these classes, making evidence-based decision-making in the treatment of painful diabetic neuropathy difficult.

Objectives: This study aimed to perform a network meta-analysis and benefit-risk analysis to evaluate the comparative efficacy and safety of these drugs in PDN treatment.

Study Design: Comparative effectiveness study.

Setting: Medical Education and Research facility in India.

Methods: A comprehensive data search was done in PubMed, Cochrane, and Embase up to August 2012. We then systematically reviewed the studies which compared any of 6 drugs for the management of PDN: amitriptyline, duloxetine, gabapentin, pregabalin, valproate, and venlafaxine or any of their combinations. We performed a random-effects network meta-analysis to rank treatments in terms of efficacy and safety. We chose the number of patients experiencing $\geq 50 \%$ reduction in pain and number of patient withdrawals due to adverse events (AE) as primary outcomes for efficacy and safety, respectively. We also performed benefit-risk analysis, taking efficacy outcome as benefit and safety outcome as risk. Analysis was intention-to-treat.

Results: We included 21 published trials in the analysis. Duloxetine, gabapentin, pregabalin, and venlafaxine were shown to be significantly efficacious compared to placebo with odds ratios (OR) of 2.12, 3.98, 2.78, and 4.43, respectively. Amitriptyline (OR: 7.03, 95\% confidence interval $[\mathrm{Cl}]: 1.87,29.05)$ and duloxetine (OR: $3.26,95 \% \mathrm{Cl}: 1.04,9.97)$ caused more withdrawals than gabapentin. The ranking order of efficacy was gabapentin, venlafaxine, pregabalin, duloxetine/ gabapentin, duloxetine, amitriptyline, and placebo and the ranking order of safety was placebo, gabapentin, pregabalin, venlafaxine, duloxetine/gabapentin combination, duloxetine, and amitriptyline. Benefit-risk balance favored the order: gabapentin, venlafaxine, pregabalin, duloxetine/gabapentin combination, duloxetine, placebo, and amitriptyline.

Limitations: We could not include valproate in our analysis owing to the lack of studies reporting the dichotomous efficacy and safety outcomes.

Conclusion: Gabapentin was found to be most efficacious and amitriptyline to be least safe among the treatments included in the study. Gabapentin showed most favorable balance between efficacy and safety.

Key words: Amitriptyline, diabetic neuropathy, duloxetine, gabapentin, network meta-analysis, pain, pregabalin, valproate, valproic acid, venlafaxine

Pain Physician 2013; 16:E705-E714 
D ainful diabetic neuropathy (PDN), a significant microvascular complication of diabetes, is characterised by the prickling, tingling, burning, electric shock like, freezing pain with allodynia and hyperalgesia in the legs, feet, and hands affecting $21 \%$ of diabetic patients $(1,2)$. It is estimated that half of the diabetic patients develop neuropathy and the prevalence of PDN ranges from 10 to $20 \%$ in diabetic patients and from 40 to $50 \%$ in those with diabetic neuropathy (3). PDN, even though common and often severe, is frequently unreported (12.5\%) and more frequently untreated (39.3\%) (4). Patients with PDN experience reduced mobility, physical activity, and enjoyment of life; fatigue; limitations in social activity; diabetic foot infections; sleep impairment; anxiety; and depression $(5,6)$. It is reported that increased age, increased duration of diabetes, and poorer glycemic control increases the risk of PDN (7).

The medications commonly used in PDN like antidepressants, anticonvulsants, opioids, and non-steroidal anti-inflammatory drugs (NSAIDs) are moderately effective and poorly tolerated (8). Anticonvulsants and antidepressants have been the mainstay of treatment in patients with PDN (9). Even though placebo controlled clinical trials of these drugs have shown them to be more effective, there exists a paucity of head-to-head comparisons between these drugs and their combinations. Systematic reviews were conducted earlier for the trials comparing the treatments used in PDN, but they have not attempted to rank the efficacy and safety of those treatments.

Network meta-analysis is a meta-analysis in which multiple treatments are compared using direct comparisons of treatments within randomized clinical trials (RCTs) and indirect comparisons across RCTs based on a common comparator (10). We did a network metaanalysis and benefit-risk analysis of RCTs comparing the anticonvulsants and antidepressants recommended by the American Academy of Neurology (11), with placebo or one another in management of PDN, to provide a comparative evaluation and to rank these drugs based on their efficacy and safety.

\section{Methods}

\section{Search Strategy}

We identified the studies (English) relevant to our network meta-analysis by performing a comprehensive search in databases like PubMed, Cochrane, and EMBASE, published between January 1980 and August
2012. Additional reports were identified from the reference lists of retrieved studies and systematic reviews. Only the published data were sought.

The key words used in the search were amitriptyline, duloxetine, gabapentin, pregabalin, valproate, valproic acid, venlafaxine, pain, and diabetic neuropathy using the filter of Clinical trials (only in PubMed). We chose only these 6 drugs, 3 each from the class of antidepressants and anticonvulsants since these were recommended as per the guidelines framed by the American Academy of Neurology in the management of PDN in adults. The pharmacokinetic and pharmacodynamic properties of included drugs are depicted in Table 1 (12).

\section{Eligibility Criteria}

We have included RCTs evaluating the usefulness of treatments in adults with PDN. Both open labelled and blinded studies were included. The included RCTs were required to report the data of both efficacy and safety, comparing one treatment with another or placebo. The treatments involved the administration of oral anticonvulsants or antidepressants. Both fixed dose and flexible dose regimens were included. The patients in the included studies were both men and women aging 18 years and older with PDN. The quality of the included studies was assessed using the Cochrane risk of bias method. We excluded those studies which were case reports, clinical observations, and long-term safety studies. Studies were excluded that presented data published in another study, and studies in which the results of PDN patients could not be segregated from patients with other types of neuropathic pain. We also excluded the studies having a sample size of less than 10 .

\section{Data Extraction}

Two reviewers independently assessed studies for eligibility and extracted the data. The disagreements were resolved through discussion with the third author. Information was extracted regarding the characteristics of studies (study design, study duration, number of patients, and treatment arms) and patients (age, duration of diabetes, duration of painful diabetic neuropathy), intervention details (dosing regimen), and outcome measures (efficacy and safety).

We sent 18 letters to authors for additional information on their published studies regarding methods of random sequence generation, allocation concealment, blinding of outcome assessment, and details of the outcome measures. Four of them replied. 
Table 1. Pharmacokinetic and Pharmacodynamic properties of included drugs.

\begin{tabular}{|c|c|c|c|c|c|c|}
\hline & \multicolumn{3}{|c|}{ Antidepressants } & \multicolumn{3}{|c|}{ Antiepileptics } \\
\hline & Duloxetine & Venlafaxine & Amitriptyline & Pregabalin & Valproate & Gabapentin \\
\hline Class & SNRI & SNRI & TCA & $\begin{array}{c}\text { Calcium channel } \alpha 2- \\
\delta \text { ligands }\end{array}$ & Miscellaneous & $\begin{array}{c}\text { Calcium channel } \\
\alpha 2-\delta \text { ligands }\end{array}$ \\
\hline $\begin{array}{l}\text { Mechanism of } \\
\text { action }\end{array}$ & $\begin{array}{c}\text { Inhibits } \\
\text { reuptake of } \\
\text { norepinephrine } \\
\text { and serotonin }\end{array}$ & $\begin{array}{c}\text { Inhibits } \\
\text { reuptake of } \\
\text { norepinephrine } \\
\text { and serotonin }\end{array}$ & $\begin{array}{l}\text { Inhibits } \\
\text { reuptake of } \\
\text { norepinephrine } \\
\text { and serotonin }\end{array}$ & $\begin{array}{l}\text { Binds to an auxiliary } \\
\text { subunit ( } 2-\delta \\
\text { protein) of voltage } \\
\text { - gated calcium } \\
\text { channels in the central } \\
\text { nervous system and } \\
\text { reduces the synaptic } \\
\text { release of several } \\
\text { neurotransmitters }\end{array}$ & $\begin{array}{l}\text { Enhances GABA } \\
\text { function } \\
\text { by binding to } \\
\text { the GABA - A } \\
\text { complex or } \\
\text { enhancing } \\
\text { GABA synthesis or } \\
\text { release }\end{array}$ & $\begin{array}{c}\text { Binds to an } \\
\text { auxiliary subunit } \\
\text { ( } \alpha 2-\delta \text { protein) } \\
\text { of voltage - gated } \\
\text { calcium channels in } \\
\text { the central nervous } \\
\text { system and reduces } \\
\text { the synaptic } \\
\text { release of several } \\
\text { neurotransmitters }\end{array}$ \\
\hline $\begin{array}{l}\text { Dose range (mg } \\
\text { per day) }\end{array}$ & $30-120$ & $37.5-225$ & $10-150$ & $150-600$ & $500-1200^{*}$ & $100-3600$ \\
\hline \multicolumn{7}{|l|}{ Pharmacokinetics } \\
\hline Bioavailability & $32-80 \%$ & $45 \%$ & $40-60 \%$ & $\geq 90 \%$ & $90 \%$ & $\begin{array}{c}\text { Saturable } \\
\text { absorption } \\
60 \% \text { for } 900 \mathrm{mg} \text { to } \\
\text { approximately } 27 \% \\
\text { for } 4800 \mathrm{mg}\end{array}$ \\
\hline $\begin{array}{l}\text { Volume of } \\
\text { distribution }(\mathrm{L} / \mathrm{kg})\end{array}$ & $10-14$ & 7.5 & 19 & 0.5 & 0.2 & $0.6-0.8$ \\
\hline $\begin{array}{l}\text { Time to reach } \\
\text { steady state } \\
\text { concentration (days) }\end{array}$ & $3-5$ & $\leq 3$ & $3-8$ & $1-2$ & $2-4$ & 2 \\
\hline $\begin{array}{l}\text { Elimination half } \\
\text { life (hours) }\end{array}$ & $8-17$ & $3-7$ & $9-27$ & $5-6.5$ & $9-19$ & $5-7$ \\
\hline Metabolism & $\begin{array}{l}\text { Hepatic, via } \\
\text { CYP1A2 and } \\
\text { CYP2D6; } \\
\text { forms multiple } \\
\text { metabolites } \\
\text { (inactive) }\end{array}$ & $\begin{array}{l}\text { Hepatic via } \\
\text { CYP2D6 } \\
\text { to active } \\
\text { metabolite, } \\
\text { O - desmethyl } \\
\text { venlafaxine }\end{array}$ & $\begin{array}{l}\text { Hepatic via } \\
\text { CYP1A2, } \\
\text { CYP2D6, } \\
\text { CYP3A4 and } \\
\text { CYP2C }\end{array}$ & Negligible & $\begin{array}{l}\text { Hepatic via } \\
\text { glucuronide } \\
\text { conjugation } \\
\text { (30\% to } 50 \% \text { of } \\
\text { administered } \\
\text { dose) and } 40 \% \text { via } \\
\text { mitochondrial beta } \\
\text { - oxidation; other } \\
\text { oxidative metabolic } \\
\text { pathways occur to a } \\
\text { lesser extent }\end{array}$ & Negligible \\
\hline $\begin{array}{l}\text { Route of } \\
\text { elimination }\end{array}$ & $\begin{array}{l}\text { Urine }(\sim 70 \% ; \\
<1 \% \text { of } \\
\text { total dose as } \\
\text { unchanged } \\
\text { drug); faeces } \\
(\sim 20 \%)\end{array}$ & $\begin{array}{c}\text { Urine }(\sim 87 \% ; 5 \% \\
\text { of total dose as } \\
\text { unchanged drug; } \\
29 \% \text { of total dose } \\
\text { as unconjugated } \\
\text { form }\end{array}$ & $\begin{array}{c}\text { Urine (18\% } \\
\text { as unchanged } \\
\text { drug); faeces } \\
\text { (small amounts) }\end{array}$ & $\begin{array}{c}\text { Urine (90\% as } \\
\text { unchanged drug; } \\
\text { minor metabolites) }\end{array}$ & $\begin{array}{l}\text { Urine }(30 \% \text { to } 50 \% \\
\text { as glucuronide } \\
\text { conjugate, }<3 \% \text { as } \\
\text { unchanged drug) }\end{array}$ & $\begin{array}{l}\text { Proportional to } \\
\text { renal function; } \\
\text { urine (as } \\
\text { unchanged drug) }\end{array}$ \\
\hline
\end{tabular}

SNRI, Serotonin and norepinephrine reuptake inhibitors; TCA, Tricyclic antidepressants; GABA, Gamma amino butyric acid

${ }^{*}$ Dose range of valproic acid was taken for the indication of diabetic painful neuropathy from the clinical trials

\section{Outcome Measures}

We defined $\geq 50 \%$ reduction in pain as the clinically relevant outcome measure for efficacy. We used a hierarchy of outcome measures for efficacy. The number of patients reporting at least $50 \%$ reduction in pain on a suitable ordinal scale "Very much improved," "much improved," or "moderately improved" on the Patient Global Impression of Change (PGIC) or Clinical Global Impression of Change (CGIC) scales or at least moderate pain relief on a suitable categorical scale $(9,13)$.

Efficacy measures after the longest duration of 
treatment were used. We selected the number of patient withdrawals due to $A E$ as outcome measures for safety. It was defined as the number of patients with major harms that lead to withdrawal from the study.

\section{Statistical Analysis}

We combined the results of all the studies and estimated the relative effects in terms of odds ratio (OR) with $95 \%$ confidence intervals $(\mathrm{Cl})$. A difference between active treatment and placebo or another active treatment was assumed to be statistically significant when the lower limit of $95 \% \mathrm{Cls}$ of the OR was > 1. Analysis was performed by the intention-to-treat principle. Multiple-treatment meta-analysis or network meta-analysis are often conducted in a Bayesian framework and estimated using Markov chain Monte Carlo methods, the approach which is recommended by the National Institute for Health and Clinical Excellence (NICE) Decision Support Unit technical support documents on evidence synthesis (14). We performed a random-effects network meta-analysis in ADDIS Version 1.14.1, the software that uses Bayesian Markov chain Monte Carlo methods. Consistency of the RCTs included in the network was checked by applying inconsistency and node-splitting models. The results were considered to show no significant inconsistency when $95 \% \mathrm{Cls}$ of inconsistency factors included zero. A large $P$-value ( $>$
0.05) for the comparison between direct and indirect effects in the node splitting analysis also indicates a lack of significant inconsistency. We estimated the ranking probability for each drug, i.e., the most efficacious or the best regimen, the second-best, the third-best, and so on, and presented the results graphically. The overall ranks were interpreted by surface under the cumulative ranking (SUCRA) technique (15). We also conducted a benefit-risk analysis by the Stochastic Multi-criteria Acceptability Analysis (SMAA) model (16) taking number of patients experiencing a $50 \%$ reduction in pain as criteria for benefit and number of patient withdrawals as criteria for risk.

\section{Results}

We had identified 3,810 titles and abstracts through literature search, excluded 3,773 titles and abstracts after initial screening, and assessed 37 full text articles for eligibility. We had finally included 21 studies published in English which compared 6 active treatments: amitriptyline, duloxetine, duloxetine/gabapentin combination gabapentin, pregabalin, and venlafaxine. Flow chart of selection process is shown in Fig. 1. RCTs evaluating valproate did not meet our eligibility criteria and hence valproate was excluded from our analysis. Seventeen trials were parallel studies and 4 trials were cross-over with wash-out in between treatment periods. Of the

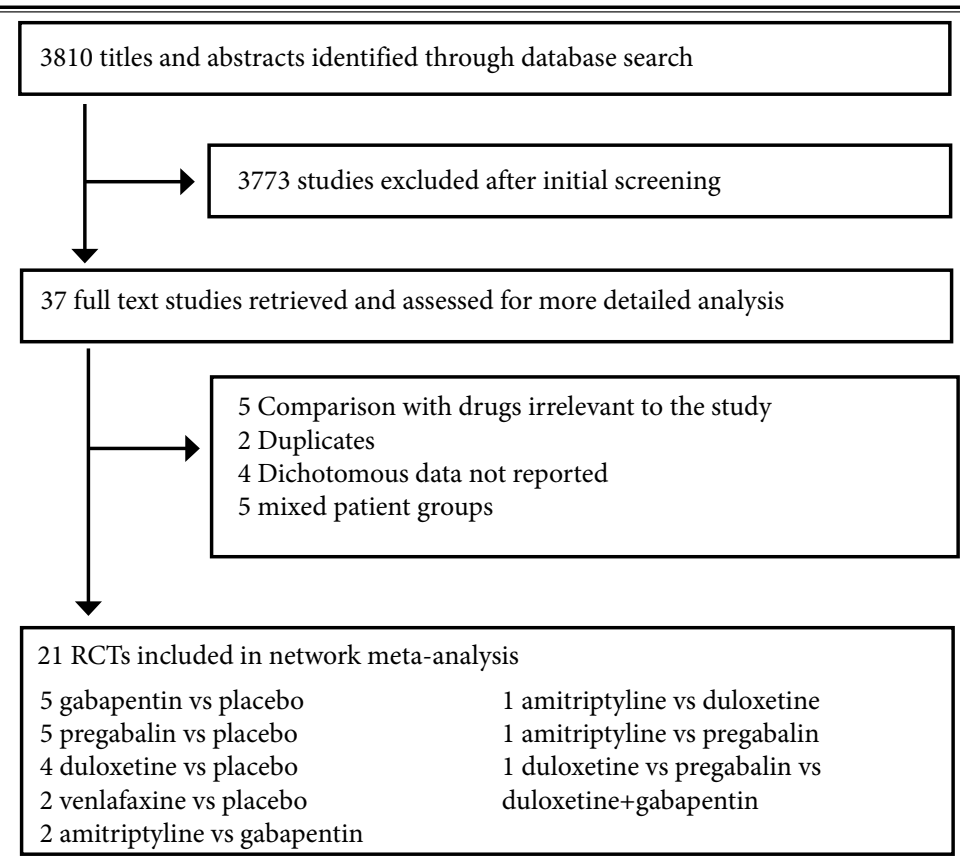

Fig 1. Flow chart of selection process. 
total studies, 16 studies were placebo controlled trials and one study didn't clearly mention randomization. Twenty-one studies (4,219 participants) contributed to the analysis of efficacy outcomes and 17 studies $(4,022$ participants) contributed to the analysis of safety outcomes. Most trials were 2 grouped studies, 5 trials were 3 grouped, and 2 trials were 4 grouped studies. Overall 4,219 patients were randomly assigned to one of the interventions including the placebo. The mean study duration of all the studies was 10.8 weeks with standard deviation of 3.2 weeks. The mean sample size was 82.7 patients per treatment group. Table 2 shows the characteristics of the included studies (20-40).
Most trials were rated to be of good methodological quality, despite most of the trials not mentioning the procedures for allocation concealment and blinding of outcome assessment.

\section{Efficacy}

Twenty-one RCTs compared 3 antidepressants, 2 anticonvulsants, and one combination. Eight trials studied gabapentin, 7 pregabalin, 6 duloxetine, 4 amitriptyline, 2 venlafaxine, and one trial studied duloxetine/gabapentin combination. Duloxetine, gabapentin, pregabalin, and venlafaxine have significantly superior relative effect compared to placebo with OR and $95 \% \mathrm{Cls}$ of

Table 2. Characteristics of included studies.

\begin{tabular}{|c|c|c|c|c|c|c|c|}
\hline Study & $\begin{array}{c}\text { Investigational } \\
\text { drugs }\end{array}$ & $\begin{array}{l}\text { Daily dose } \\
\text { (mg) }\end{array}$ & $\begin{array}{l}\text { Group } \\
\text { allocation }\end{array}$ & Blinding & $\begin{array}{l}\text { Study } \\
\text { size }\end{array}$ & Design & $\begin{array}{c}\text { Study } \\
\text { duration }\end{array}$ \\
\hline Arezzo et al, 2008 (20) & ${ }^{* * \text { Pregabalin }}$ & 600 & $\mathrm{R}$ & DB & 167 & Parallel & 13 weeks \\
\hline Backonja et al, 1998 (21) & ${ }^{*}$ Gabapentin & $900-3600$ & $\mathrm{R}$ & DB & 165 & Parallel & 8 weeks \\
\hline $\begin{array}{l}\text { Bansal et al, } \\
2009(22)\end{array}$ & $\begin{array}{l}\text { Amitriptyline } \\
\text { Pregabalin }\end{array}$ & $\begin{array}{c}10-50 \\
150-600\end{array}$ & $\mathrm{R}$ & DB & 102 & $\begin{array}{c}\text { Cross over, } 2 \\
\text { week wash out }\end{array}$ & 14 weeks \\
\hline Dallocchio et al, 2000 (23) & $\begin{array}{c}\text { Gabapentin } \\
\text { Amitriptyline }\end{array}$ & $\begin{array}{c}1200-2400 \\
30-90\end{array}$ & $\mathrm{R}$ & OL & 25 & Parallel & 12 weeks \\
\hline Goldstein et al, 2005 (24) & ${ }^{*}$ Duloxetine & $20,60,120$ & $\mathrm{R}$ & DB & 457 & Parallel & 12 weeks \\
\hline Gorson et al, 1999 (25) & ${ }^{\star}$ Gabapentin & $300-900$ & $\mathrm{R}$ & DB & 80 & $\begin{array}{c}\text { Cross over, } 3 \\
\text { week wash out }\end{array}$ & 15 weeks \\
\hline Kadiroglu et al, 2008 (26) & ${ }^{*}$ Venlafaxine & 75 & $\mathrm{R}$ & $\mathrm{U}$ & 60 & Parallel & 8 weeks \\
\hline Kaur et al, 2011 (27) & $\begin{array}{l}\text { Amitriptyline } \\
\text { Duloxetine }\end{array}$ & $\begin{array}{l}20-60 \\
10-50\end{array}$ & $\mathrm{R}$ & DB & 130 & $\begin{array}{c}\text { Cross over, } 2 \\
\text { week wash out }\end{array}$ & 14 weeks \\
\hline Lesser et al, 2004 (28) & ${ }^{\star}$ Pregabalin & 300,600 & $\mathrm{R}$ & DB & 337 & Parallel & 5 weeks \\
\hline Morella et al, 1999 (29) & $\begin{array}{c}\text { Gabapentin } \\
\text { Amitriptyline }\end{array}$ & $\begin{array}{l}900-1800 \\
25-75\end{array}$ & $\mathrm{R}$ & DB & 50 & $\begin{array}{l}\text { Cross over, one } \\
\text { week wash out }\end{array}$ & 13 weeks \\
\hline Raskin et al, 2005 (30) & ${ }^{*}$ Duloxetine & 60,120 & $\mathrm{R}$ & DB & 348 & Parallel & 12 weeks \\
\hline Rosenstock et al, 2004 (31) & ${ }^{\star}$ Pregabalin & 300 & $\mathrm{R}$ & DB & 146 & Parallel & 8 weeks \\
\hline Rowbotham et al, 2004 (32) & ${ }^{*}$ Venlafaxine & $150-225$ & $\mathrm{R}$ & DB & 245 & Parallel & 6 weeks \\
\hline Sandercock, 2012 (33) & ${ }^{\star}$ Gabapentin & $\begin{array}{c}3000,1200 \& \\
1800 \text { (div) }\end{array}$ & $\mathrm{R}$ & DB & 147 & Parallel & 4 weeks \\
\hline Satoh et al, 2011 (34) & ${ }^{\star}$ Pregabalin & 300,600 & $\mathrm{R}$ & DB & 317 & Parallel & 14 weeks \\
\hline Simpson, 2001 (35) & ${ }^{*}$ Gabapentin & $300-3600$ & $\mathrm{R}$ & DB & 60 & Parallel & 8weeks \\
\hline $\begin{array}{l}\text { Perez and Sanchez, } 2000 \\
\text { (36) }\end{array}$ & ${ }^{*}$ Gabapentin & $600-1200$ & $\mathrm{U}$ & DB & 32 & Parallel & 3 months \\
\hline Tanenberg et al, 2011 (37) & $\begin{array}{l}\text { Dul/Gbp } \\
\text { Pregabalin } \\
\text { Duloxetine }\end{array}$ & $\begin{array}{c}60 / 900-3600 \\
300 \\
60 \\
\end{array}$ & $\mathrm{R}$ & OL & 407 & Parallel & 12 weeks \\
\hline Tolle et al, 2008 (38) & ${ }^{*}$ Pregabalin & $150,300,600$ & $\mathrm{R}$ & DB & 395 & Parallel & 12 weeks \\
\hline Wernicke et al, 2006 (39) & ${ }^{*}$ Duloxetine & $-60,120$ & $\mathrm{R}$ & DB & 334 & Parallel & 12 weeks \\
\hline Gao et al, $2010(40)$ & ${ }^{*}$ Duloxetine & $60-120$ & $\mathrm{R}$ & $\mathrm{DB}$ & 215 & Parallel & 12 weeks \\
\hline
\end{tabular}

* - indicates Placebo also used as investigational drug with daily does not indicated. $\mathrm{R}=$ Randomized, $\mathrm{U}=$ Unknown, $\mathrm{DB}=\mathrm{Double}-\mathrm{blind}, \mathrm{OL}=$ Open label, Dul/Gbp = Duloxetine/Gabapentin combination 
Table 3. Relative effects of efficacy (number of patients experiencing least $50 \%$ reduction in pain) and safety (number of patient withdrawals due to adverse events) of drugs.

\begin{tabular}{|c|c|c|c|c|c|c|}
\hline \hline Amitriptyline & $0.46(0.15,1.34)$ & $0.33(0.08,1.30)$ & $0.14(0.03,0.53)$ & $0.10(0.03,0.29)$ & $0.31(0.11,0.87)$ & $0.31(0.04,2.30)$ \\
\hline $\begin{array}{c}0.92 \\
(0.42,2.00)\end{array}$ & Duloxetine & $0.72(0.29,1.90)$ & $0.31(0.10,0.96)$ & $0.21(0.12,0.36)$ & $0.66(0.36,1.30)$ & $0.67(0.12,4.37)$ \\
\hline $\begin{array}{c}0.85 \\
(0.24,2.94)\end{array}$ & $\begin{array}{c}0.93 \\
(0.33,2.67)\end{array}$ & $\begin{array}{c}\text { Duloxetine }+ \\
\text { Gabapentin }\end{array}$ & $0.42(0.10,1.65)$ & $0.30(0.11,0.79)$ & $0.93(0.36,2.36)$ & $0.92(0.15,7.02)$ \\
\hline $\begin{array}{c}0.49 \\
(0.21,1.09)\end{array}$ & $\begin{array}{c}0.53 \\
(0.24,1.07)\end{array}$ & $\begin{array}{c}0.58 \\
(0.16,1.83)\end{array}$ & Gabapentin & $0.70(0.25,1.85)$ & $2.18(0.73,6.68)$ & $2.18(0.34,15.22)$ \\
\hline $\begin{array}{c}2.95 \\
(0.90,4.26)\end{array}$ & $\begin{array}{c}2.27 \\
(1.29,3.50)\end{array}$ & $\begin{array}{c}3.98 \\
(2.29,7.68)\end{array}$ & Placebo & $3.14(1.87,5.46)$ & $3.12(0.67,18.57)$ \\
\hline $\begin{array}{c}0.71 \\
(0.30,1.54)\end{array}$ & $\begin{array}{c}0.82 \\
(0.41,1.40)\end{array}$ & $\begin{array}{c}1.44 \\
(0.71,3.06)\end{array}$ & $\begin{array}{c}0.36 \\
(0.22,0.58)\end{array}$ & Pregabalin & $0.99(0.19,6.36)$ \\
\hline $\begin{array}{c}0.44 \\
(0.11,1.45)\end{array}$ & $\begin{array}{c}0.15,1.32) \\
(0.11,1.96)\end{array}$ & $\begin{array}{c}0.90 \\
(0.28,2.72)\end{array}$ & $\begin{array}{c}0.23 \\
(0.08,0.55)\end{array}$ & $\begin{array}{c}0.63 \\
(0.19,1.74)\end{array}$ & Venlafaxine \\
\hline
\end{tabular}

Note: The numbers in the cell represent the odds ratio (95\% credibility interval) of the column defining treatment relative to the row defining treatment $\square$ Efficacy (OR with 95\% CrI) $\square$ Safety (OR with 95\% CrI)

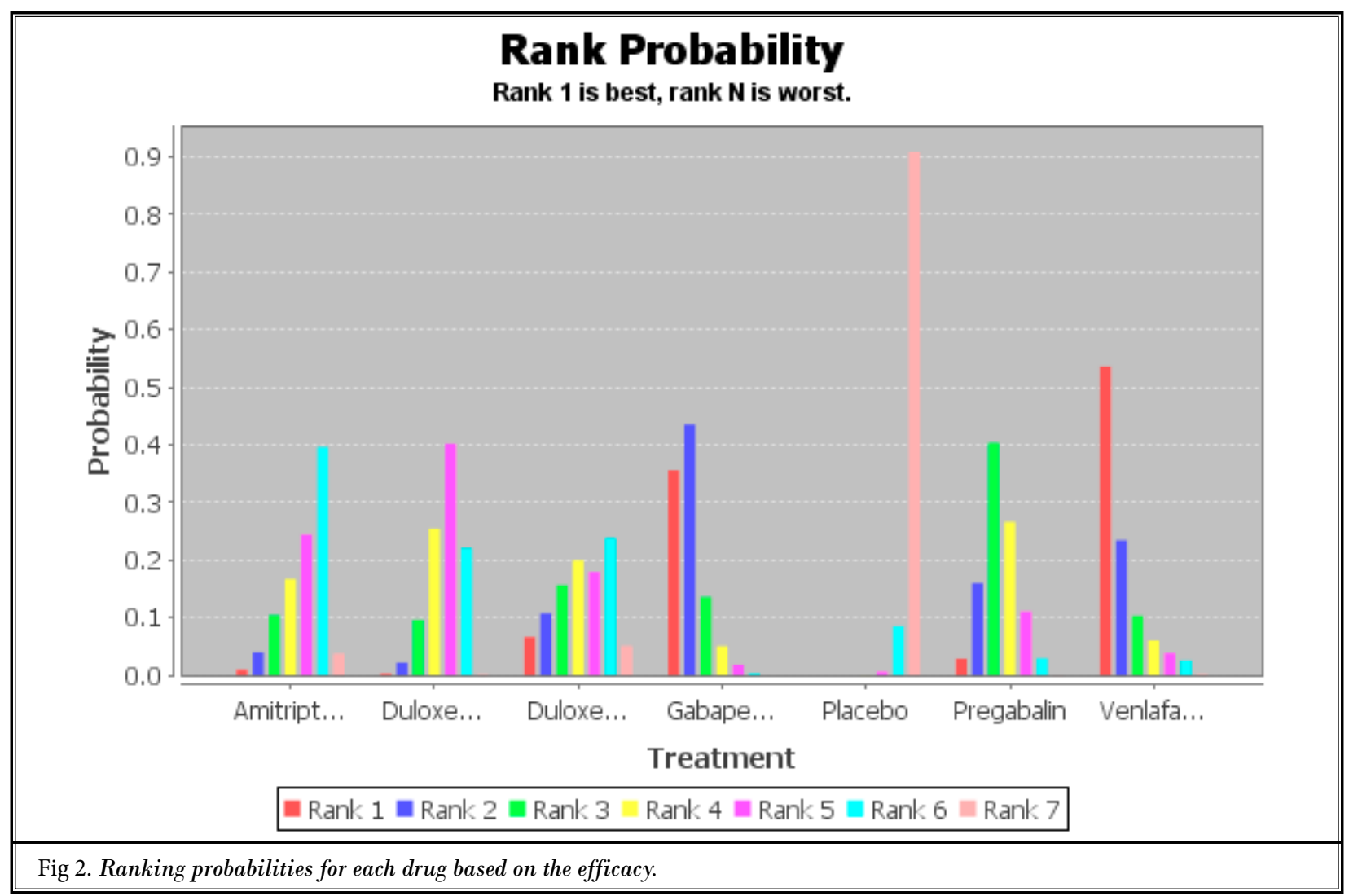

$2.12(1.29,3.5), 3.98(2.29,7.68), 2.78(1.72,4.62)$, and $4.43(1.81,12.93)$, respectively, as shown in Table 3. No significant difference in the relative effect was found between the active comparators. Venlafaxine (OR: 1.59, $95 \% \mathrm{Cl}: 0.57,5.2$ ) and gabapentin (OR: $1.44,95 \% \mathrm{Cl}$ : $0.71,3.06$ ) were shown to be more efficacious than pregabalin, though it was not statistically significant. Gabapentin was shown to be the most efficacious treatment followed by venlafaxine, pregabalin, duloxetine/ gabapentin, duloxetine, amitriptyline, and placebo. The ranking was given according to the ranking probabilities shown in the Fig. 2 . 
The results were shown to be consistent from the inconsistency model analysis and node-splitting analysis. Inconsistency factors measured as median $(95 \%$ $\mathrm{Cl})$ for the loops amitriptyline, duloxetine, pregabalin was $-0.03(-1.33,0.91)$, amitriptyline, duloxetine, gabapentin, placebo, pregabalin was $0.01(-1.09,1.18)$, and duloxetine, placebo, pregabalin was $0.07(-0.63,1.1)$.

\section{Safety}

We considered the number of patient withdrawals due to AE as outcome for safety. Seventeen RCTs compared 3 antidepressants, 2 anticonvulsants, and one combination. Seven trials studied pregabalin, 6 duloxetine, 4 gabapentin, 3 amitriptyline, one venlafaxine, and one trial studied duloxetine/gabapentin combination. The number of patient withdrawals due to $A E$ was significantly higher for amitriptyline, duloxetine, duloxetine/gabapentin, and pregabalin compared to placebo with OR $(\mathrm{Cl})$ of $10.24(3.49,31.19), 4.69(2.74,8.17), 3.38$ $(1.27,9.39)$, and $3.14(1.87,5.46)$, respectively, as shown in Table 3. In the active treatment comparisons, amitriptyline (OR: $7.03,95 \% \mathrm{Cl}: 1.87,29.05)$ and duloxetine (OR: $3.26,95 \% \mathrm{Cl}: 1.04,9.97)$ caused significantly more withdrawals due to $A E$ than gabapentin. Amitriptyline caused most patient withdrawals due to AE followed by duloxetine, duloxetine/gabapentin combination, ven- lafaxine, pregabalin, gabapentin, and placebo based on ranking probabilities shown in Fig. 3. The results were consistent with inconsistency factors for loops amitriptyline, duloxetine, pregabalin; and amitriptyline, duloxetine, gabapentin, placebo, pregabalin; and duloxetine, placebo, pregabalin being $0.03(-1.2,1.42)$, $-0.1(-2.15,1.17)$, and $0.21(-0.52,1.46)$, respectively.

\section{Benefit-risk Analysis}

We conducted a benefit-risk analysis taking the number of patients experiencing a $50 \%$ reduction in pain as criteria for benefit and number of patient withdrawals due to $A E$ as criteria for risk. Thus, 21 studies contributed to benefit and 17 studies contributed to risk criteria. The log-odds ratio, or mean difference, with placebo as the common comparator for amitriptyline, duloxetine, duloxetine/gabapentin, gabapentin, pregabalin, and venlafaxine was respectively $0.67 \pm 0.39,0.75$ $\pm 0.25,0.83 \pm 0.53,1.39 \pm 0.30,1.02 \pm 0.25,1.51 \pm 0.50$ for benefit and $2.32 \pm 0.56,1.55 \pm 0.29,1.22 \pm 0.51,0.34$ $\pm 0.51,1.15 \pm 0.27$, and $1.12 \pm 0.83$ for risk. The most favorable balance between benefit and risk was shown for gabapentin followed by venlafaxine, pregabalin, duloxetine/gabapentin combination, placebo, duloxetine, and amitriptyline. Ranking probabilities for each drug based on the benefit-risk balance is shown in Fig. 4 .

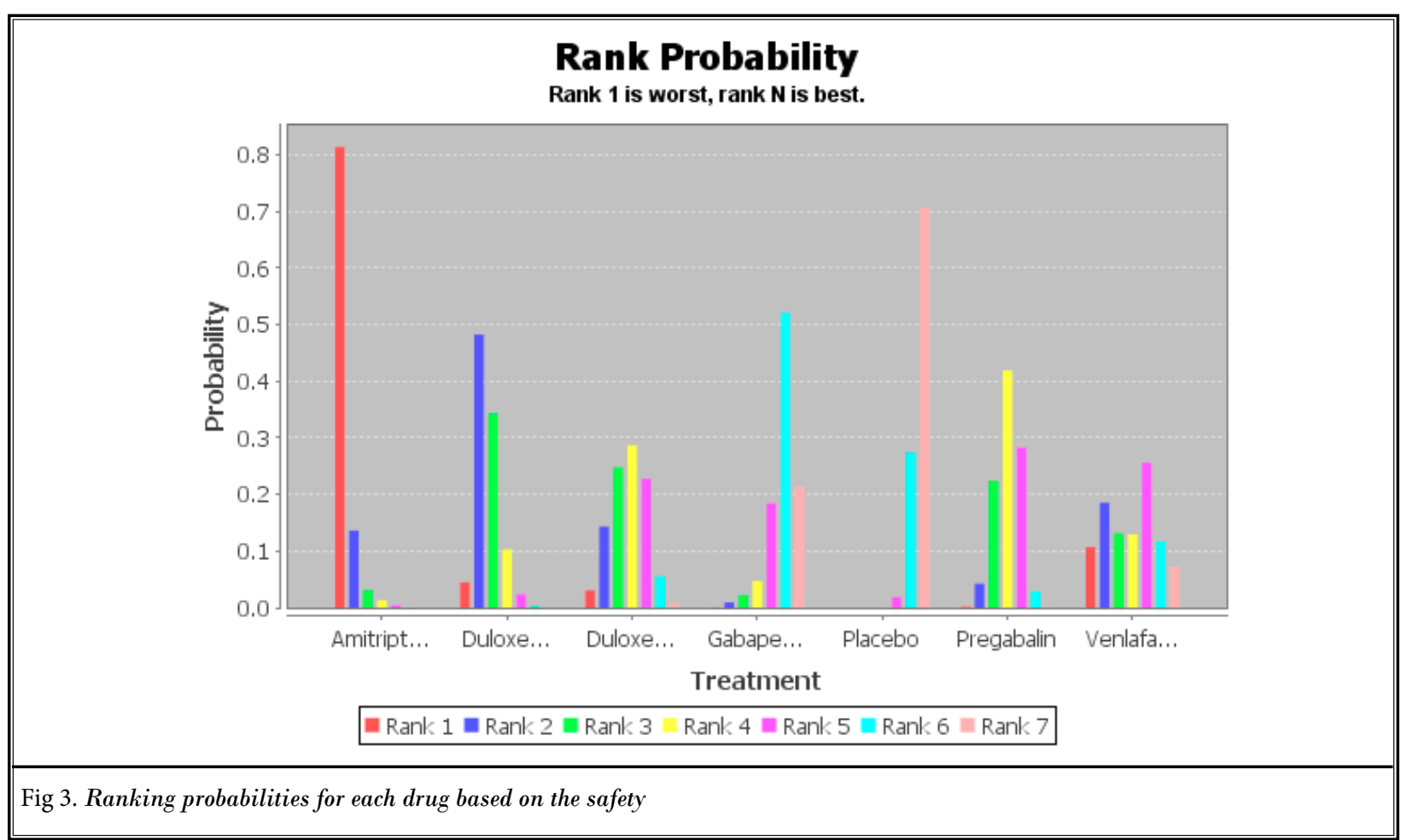




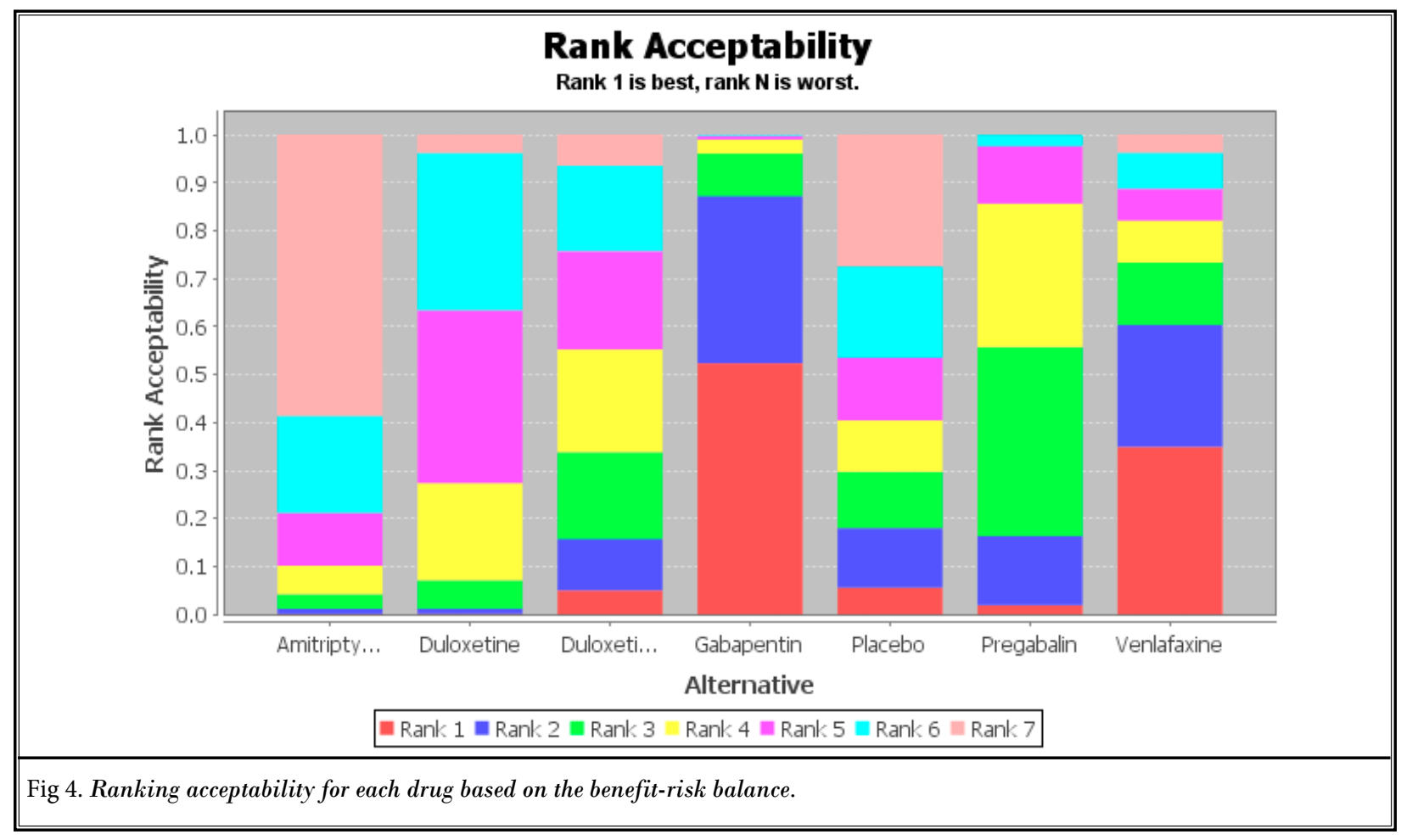

\section{Discussion}

We conducted a network meta-analysis for the comparison of efficacy and safety of the first line antidepressants and anticonvulsants used in the treatment of PDN. This analysis makes it possible the indirect comparison of active treatments where direct head to head comparisons were lacking. We aimed to include 6 treatments, 3 each from the class of antidepressants and anticonvulsants: amitriptyline, duloxetine, gabapentin, pregabalin, valproate, and venlafaxine, which are considered to have scientifically sound and clinically relevant evidence as per the guidelines framed by the American Academy of Neurology. But we could not include valproate in our analysis owing to the lack of studies reporting the dichotomous efficacy and safety outcomes. One study reported the dichotomous outcome for efficacy, but only in the valproate arm and not in the placebo arm, leading to exclusion of that study.

It was found that many clinical trials fail to predict outcome because they often include a small sample size. In a study conducted by Moore et al (17), it was shown that only large trials could possibly determine efficacy of a treatment. In such cases it may be imperative to pool up the individual studies and generate the sufficient sample size to determine the usefulness of a specific drug. Conventional meta-analyses are limited by their ability to access only the evidence from direct comparisons between 2 treatments. Network metaanalysis expands the scope of a conventional pair-wise meta-analysis by simultaneously analyzing both direct and indirect comparisons of multiple interventions.

PDN is a chronic disease and the effects of treatments on the progression of disease need to be considered. The treatment period of the studies included in our analysis was less than 4 months. Thus, the efficacy and the safety of these treatments over a longer period of time could not be evaluated. We have excluded the long-term safety studies of the treatments from our analysis because they report only the safety outcomes and possible inclusion of such studies was thought to induce inconsistency and affect the overall results of the network meta-analysis. In this study, we have included $50 \%$ reduction in pain as the primary outcome for efficacy since it is considered to be a gold standard in the evaluation of pain relief. However, in a trial conducted by Kadiroglu et al, the authors have reported $60 \%$ reduction in pain, which we considered to be similar to $50 \%$ reduction in pain and included in the analysis. $A E$ reported in the studies were diverse because the drugs belong to different classes. We did not investigate the 
specific side effects; however, we found the incidence of cardinal $A E$, namely peripheral edema and euphoria, in patients on pregabalin in ranges of (3.9\% to $36.6 \%)$ and $(3.7 \%$ to $6.2 \%)$, respectively. While performing the benefit-risk analysis, we could not assign the $A E$ to risk since nausea was the only common $\mathrm{AE}$ among all the drugs. Nausea being a common AE for any drug, we could not rely on it as a criteria for risk. Hence, we chose the number of patient withdrawals due to $A E$ as the criteria for risk.

The results of our study was found to be consistent with the study conducted by Boyle et al (18), which showed no significant difference between amitriptyline, duloxetine, and pregabalin. Another trial conducted by Devi et al (19) comparing gabapentin, duloxetine, and pregabalin showed no significant difference between the treatments with pregabalin demonstrating a superior onset of pain reduction. In our analysis, gabapentin was shown to be the most efficacious drug followed by venlafaxine among the treatments analyzed. This might be due to the lack of sufficient number of studies (only 2 studies comparing venlafaxine were included in the analysis) or due to the assumption made by the authors in the study by Kadiroglu et al (26). We could not include any trials comparing amitriptyline with placebo in our study since the 2 trials $(18,19)$ comparing them did not report the dichotomous data in one of the treatment arms. We have also excluded 5 trials comparing pregabalin and placebo since they included mixed patient population, i.e., patients with both PDN and post herpetic neuralgia.

The results from our analysis emphasize the need for conducting longer duration trials and studies comparing the active treatments. It is proposed to use common pain measurement scales for evaluation of pain relief and also to include the dichotomous data in the trials. Even though treatment guidelines for the management of PDN are available, it is suggested that treatment should be given by the physician, taking the patient's response into consideration.

\section{Conclusion}

The treatments included in the analysis were shown to be superior to placebo in relieving pain, but no significant superiority was shown among the active treatments. Gabapentin demonstrated the best efficacy and amitriptyline showed the least safety among the treatments included. Gabapentin was found to have the most favorable balance between benefit and risk.

\section{References}

1. Apfel SC, Asbury AK, Bril V, Burns TM, Campbell JN, Chalk $\mathrm{CH}$, Dyck PJ, Dyck PJB, Feldman EL, Fields HL, Grant IA, Griffin JW, Klein CJ, Lindblom U, Litchy WJ, Low PA, Melanson M, Mendell JR, Merren MD, O'Brien PC, Rendell M, Rizza RA, Service FJ, Thomas PK, Walk D, Wang AK, Wessel K, Windebank AJ, Ziegler D, Zochodne DW. Positive neuropathic sensory symptoms as endpoints in diabetic neuropathy trials. Neurol Sci 2001; 189:3-5.

2. Abbott CA, Malik RA, van Ross ER, Kulkarni J, Boulton AJ. Prevalence and characteristics of painful diabetic neuropathy in a large community-based diabetic population in the U.K. Diabetes Care 2011; 34:2220-2224.

3. Veves A, Backonja M, Malik RA. Painful diabetic neuropathy: Epidemiology, natural history, early diagnosis, and treatment options. Pain Med 2008; 9:660-674.

4. Daousi C, MacFarlane IA, Woodward A, Nurmikko TJ, Bundred PE, Benbow SJ. Chronic painful peripheral neuropathy in an urban community: A controlled comparison of people with and without diabetes. Diabet Med 2004; 21:976-982.

5. Gore M, Brandenburg NA, Dukes E, Hoffman DL, Tai KS, Stacey B. Pain severity in diabetic peripheral neuropathy is associated with patient functioning, symptom levels of anxiety and depression, and sleep. J Pain Symptom Manage 2005; 30:374-385.

6. Schmader KE. Epidemiology and impact on quality of life of postherpetic neuralgia and painful diabetic neuropathy. Clin J Pain 2002; 18:350-354.

7. Franklin GM, Shetterly SM, Cohen JA, Baxter J, Hamman RF. Risk factors for distal symmetric neuropathy in NIDDM. The San Luis Valley Diabetes Study. Diabetes Care 1994; 17:1172-1177.

8. Vinik Al, Tuchman M, Safirstein B, Corder C, Kirby L, Wilks K, Quessy S, Blum D, Grainger J, White J, Silver M. Lamotrigine for treatment of pain associated with diabetic neuropathy: Results of two randomized, double-blind, placebo-controlled studies. Pain 2007; 128:169-179.

9. Collins SL, Moore RA, McQuay HJ, Wiffen P. Antidepressants and anticon- vulsants for diabetic neuropathy and postherpetic neuralgia: A quantitative systematic review. J Pain Symptom Manage 2000; 20:449-458.

10. Li T, Puhan MA, Vedula SS, Singh S, Dickersin K. Network meta-analysis-highly attractive but more methodological research is needed. BMC Med 2011; 9:79.

11. Bril V, England J, Franklin GM, Backonja $M$, Cohen J, Toro DD, Feldman E, Iverson DJ, Perkins B, Russell JW, Zochodne D. Evidence-based guideline: Treatment of painful diabetic neuropathy: Report of the American Academy of Neurology, the American Association of Neuromuscular and Electrodiagnostic Medicine, and the American Academy of Physical Medicine and Rehabilitation. Neurology 2011; 76:1758-1765.

12. Lexicomp. Lexi-Drugs Online (2013). Available from: http://online.lexi.com/ Ico/action/index/dataset/patch_f. Accessed June 22, 2013.

13. Wong MC, Chung JW, Wong TK. Effects of treatments for symptoms of painful diabetic neuropathy: Systematic review. 
BMJ 2007; 335:87.

14. Dias S, Sutton AJ, Ades AE, Welton NJ. NICE DSU technical support document 2: A generalized linear modeling framework for pairwise and network metaanalysis of randomized controlled trials. www.nicedsu.org.uk.

15. Salanti G, Ades AE, loannidis JPA. Graphical methods and numerical summaries for presenting results from multiple-treatment meta-analysis: An overview and tutorial. J Clin Epidemiol 2011; 64:163-171.

16. Tervonen T, Valkenhoef GV, Buskens E, Hillege HL, Postmus D. A stochastic multicriteria model for evidence-based decision making in drug benefit-risk analysis. Stat Med 2011; 30:1419-1428.

17. Moore RA, Gavaghan D, Tramer MR, Collins SL, McQuay HJ. Size is everything-large amounts of information are needed to overcome random effects in estimating direction and magnitude of treatment effects. Pain 1998; 78:209-216.

18. Boyle J, Eriksson MEV, Gribble L, Gouni R, Johnsen S, Coppini DV, Kerr D. Randomized, placebo-controlled comparison of amitriptyline, duloxetine, and pregabalin in patients with chronic diabetic peripheral neuropathic pain. Impact on pain, polysomnographic sleep, daytime functioning, and quality of life. Diabetes Care 2012; 35:2451-2458.

19. Devi P, Madhu K, Ganapathy B, Sarma G, John L, Kulkarni C. Evaluation of efficacy and safety of gabapentin, duloxetine, and pregabalin in patients with painful diabetic peripheral neuropathy. Indian J Pharmacol 2012; 44:51-56.

20. Arezzo JC, Rosenstock J, Lamoreaux L, Pauer L. Efficacy and safety of pregabalin $600 \mathrm{mg} / \mathrm{d}$ for treating painful diabetic peripheral neuropathy: A double-blind placebo-controlled trial. BMC Neurol 2008; 8:33.

21. Backonja M, Beydoun A, Edwards KR, Schwartz SL, Fonseca V, Hes M, La Moreaux L, Garofalo E. Gabapentin for the symptomatic treatment of painful neuropathy in patients with diabetes mellitus: $A$ randomized controlled trial. JAMA 1998; 280:1831-1836.

22. Bansal D, Bhansali A, Hota D, Chakrabarti A, Dutta P. Amitriptyline vs. prega- balin in painful diabetic neuropathy: A randomized double blind clinical trial. Diabet Med 2009; 26:1019-1026.

23. Dallocchio C, Buffa C, Mazzarello P, Chiroli S. Gabapentin vs. amitriptyline in painful diabetic neuropathy: An openlabel pilot study.J Pain Symptom Manage 2000; 20:280-285.

24. Goldstein DJ, Lu Y, Detke MJ, Lee TC, lyengar $\mathrm{S}$. Duloxetine vs. placebo in patients with painful diabetic neuropathy. Pain 2005; 116:109-118.

25. Gorson KC, Schott C, Herman R, Ropper AH, Rand WM. Gabapentin in the treatment of painful diabetic neuropathy: A placebo controlled, double blind, crossover trial. J Neurol Neurosurg Psychiatry 1999; 66:251-252.

26. Kadiroglu AK, Sit D, Kayabasi H, Tuzcu AK, Tasdemir N, Yilmaz ME. The effect of venlafaxine $\mathrm{HCl}$ on painful peripheral diabetic neuropathy in patients with type 2 diabetes mellitus.] Diabetes Complications 2008; 22:241-245.

27. Kaur $\mathrm{H}$, Hota D, Bhansali A, Dutta $P$, Bansal D, Chakrabarti A. A comparative evaluation of amitriptyline and duloxetine in painful diabetic neuropathy: A randomized, double-blind, crossover clinical trial. Diabetes Care 2011; 34:818-822.

28. Lesser H, Sharma U, LaMoreaux L, Poole RM. Pregabalin relieves symptoms of painful diabetic neuropathy: $A$ randomized controlled trial. Neurology 2004; 63:2104-2110.

29. Morello CM, Leckband SG, Stoner CP, Moorhouse DF, Sahagian GA. Randomized double-blind study comparing the efficacy of gabapentin with amitriptyline on diabetic peripheral neuropathy pain. Arch Intern Med 1999; 159:1931-1937.

30. Raskin J, Pritchett YL, Wang F, D'Souza $\mathrm{DN}$, Waninger AL, lyengar $S$, Wernicke JF. A double-blind, randomized multicenter trial comparing duloxetine with placebo in the management of diabetic peripheral neuropathic pain. Pain Med 2005; 6:346-356.

31. Rosenstock J, Tuchman M, LaMoreaux L, Sharma U. Pregabalin for the treatment of painful diabetic peripheral neuropathy: A double-blind, placebo-controlled trial. Pain 2004; 110:628-638.
32. Rowbotham MC, Goli V, Kunz NR, Lei D. Venlafaxine extended release in the treatment of painful diabetic neuropathy: A double-blind, placebo-controlled study. Pain 2004; 110:697-706.

33. Sandercock D, Cramer M, Biton V, Cowles VE. A gastroretentive gabapentin formulation for the treatment of painful diabetic peripheral neuropathy: Efficacy and tolerability in a double-blind, randomized, controlled clinical trial. Diabetes Res Clin Pract 2012; 97:438-445.

34. Satoh J, Yagihashi S, Baba M, Suzuki M, Arakawa A, Yoshiyama T, Shoji S. Efficacy and safety of pregabalin for treating neuropathic pain associated with diabetic peripheral neuropathy: A 14 week, randomized, double-blind, placebo-controlled trial. Diabet Med 2011; 28:109-116.

35. Simpson DA. Gabapentin and venlafaxine for the treatment of painful diabetic neuropathy. J Clin Neuromuscul Dis 2001; 3:53-62.

36. Perez HE, Sanchez GF. Gabapentin therapy for diabetic neuropathic pain. Am J Med 2000; 108:689.

37. Tanenberg RJ, Irving GA, Risser RC, Ahl J, Robinson MJ, Skljarevski V, Malcolm SK. Duloxetine, pregabalin, and duloxetine plus gabapentin for diabetic peripheral neuropathic pain management in patients with inadequate pain response to gabapentin: An open-label, randomized, noninferiority comparison. Mayo Clin Proc 2011; 86:615-626.

38. Tolle T, Freynhagen R, Versavel M, Trostmann U, Young JP, Jr. Pregabalin for relief of neuropathic pain associated with diabetic neuropathy: A randomized, double-blind study. Eur J Pain 2008; 12:203-213.

39. Wernicke JF, Pritchett YL, D'Souza DN, Waninger A, Tran P, lyengar S, Raskin J. A randomized controlled trial of duloxetine in diabetic peripheral neuropathic pain. Neurology 2006; 67:1411-1420.

40. Gao Y, Ning G, Jia WP, Zhou ZG, Xu ZR, Liu ZM, Liu C, Ma JH, Li Q, Cheng LL, Zhang SY, Zhang QI, Desaiah D, Skljarevski V. Duloxetine versus placebo in the treatment of patients with diabetic neuropathic pain in China. Chin Med J (Engl) 2010; 123:3184-3192. 